\title{
KARAKTERISASI TEKANAN AIR PANAS PADA ORGANIC RANKINE CYCLE BERBASIS SOLAR KOLEKTOR PIPA SIRIP JENIS LONGITUDINAL
}

\author{
Dwi Yanto ${ }^{1}$, Yogi Sirodz Gaos ${ }^{2}$, Hablinur Alkindi ${ }^{3}$ \\ ${ }^{123}$ Fakultas Teknik dan Sains, Universitas Ibn Khaldun Bogor \\ e-mail: dwi27yanto@gmail.com
}

\begin{abstract}
ABSTRAK
Sistem Organic Rankine Cycle (ORC) Kolektor Surya menggunakan air sebagai fluida dan sistem sirkulasi air panas. Pipa sirip jenis longitudinal digunakan karena jenis pipa yang sangat baik untuk aplikasi perpindahan panas. Tekanan dalam laju aliran sirkulasi air panas berpengaruh terhadap sistem ORC agar berjalan secara optimal. Oleh karena itu, dalam penelitian ini dilakukan perhitungan jumlah tekanan pada sistem sirkulasi air panas untuk mengetahui apakah terdapat head loss (mayor dan minor) yang terjadi dan faktor yang mempengaruhi terjadinya head loss pada sistem sirkulasi air panas. Dari hasil pengujian dan perhitungan dalam menganalisis tekanan pada sistem sirkulasi air panas, diperoleh data head loss mayor sebesar 3,093769m, head loss minor sebesar 2,762065 m, dan head loss pada evaporator sebesar 0,00002 m, dengan total head loss sebesar 5,855853m. Berdasarkan hasil perhitungan, penggunaan pipa sirip longitudinal pada sistem perpipaan sirkulasi air panas tidak bekerja secara optimal karena head loss yang terjadi pada pengujian ini lebih besar dari pada head loss perhitungan teoritis yakni $17 \mathrm{~m}$ berbanding dengan $5,855853 \mathrm{~m}$, terdapat selisih yang cukup besar yakni sebesar $11,144147 \mathrm{~m}$. Faktor yang mempengaruhi terjadinya head loss pada sistem sirkulasi air panas yaitu banyaknya sambungan las pada pipa, kekasaran ekivalen pada material pipa, dan jenis material serta diameter pipa yang beragam sehingga tekanan air yang terjadi pada saat sirkulasi berubah-ubah.
\end{abstract}

Kata kunci : evaporator, head loss, ORC, sirkuliasi air panas, tekanan.

\begin{abstract}
Organic Rankine Cycle (ORC) System Solar collectors use water as their working fluid and the hot water circulation system. Longitudinal fin pipe is used because it is very good for heat transfer applications. Pressure in the hot water circulation flow rate influences the ORC system to run optimally. Therefore, in this study, the calculation of the amount of pressure in the hot water circulation system was carried out to find out whether there is a head loss (major \& minor) that occurs and the factors that influence of head loss in the hot water circulation system. Based on he results of testing and calculations in analyzing the pressure in the hot water circulation system, data is obtained: head loss along the hot water circulation flow, including the major head loss of 3,09376 m, minor head loss of 2,762065m, and the head loss in the evaporator of 0,00002 $\mathrm{m}$, with a total head loss of 5,855853m. Based on the results of calculations, the use of longitudinal fin pipes in hot water circulation piping systems does not work optimally because the head loss that occurs in this test is greater than the head loss theoretical calculation which is $17 \mathrm{~m}$ compared to $5,855853 \mathrm{~m}$, there is a considerable difference of $11,144147 \mathrm{~m}$. The factors influencing the occurrence of head loss in the hot water circulation system include the number of welded joints in the pipe, the roughness equivalent to the pipe material, and the variety of material types and pipe diameters, so that water pressure occurs when the circulation changes.
\end{abstract}

Keywords : evaporator, head loss, hot water circulation, pressure, ORC.

\section{PENDAHULUAN}

Kebijakan energi berkelanjutan (sustainable energy) semakin mendapat perhatian yang luas seiring dengan peningkatan pemanasan global. Kebijakan ini mempunyai dua kata kunci, yaitu peningkatan efisiensi energi dan usaha- usaha mencari sumber-sumber energi baru dan terbarukan.

Sebuah inovasi untuk dapat memenuhi kebutuhan akan ketersediaan listrik salah satunya adalah Organic Rankine Cycle (ORC). ORC dikembangkan oleh William John Macqourn 
Rankine pada desember 1872. ORC merupakan siklus pembangkit listrik yang menggunakan cairan organik bukan air sebagai fluida kerja. Siklus ORC dapat disesuaikan dengan kisaran suhu yang besar untuk menghasilkan energi, terutama untuk energi pada suhu rendah di bawah $120^{\circ} \mathrm{C}$ (Ksayer, 2011). Sistem ini menggunakan temperatur dan tekanan rendah untuk menghasilkan uap refrigeran. Uap rifrigeran tersebut digunakan untuk menggerakan turbin yang terkopel dengan generator yang selanjutnya akan mampu menghasilkan energi listrik (Ksayer, 2011).

Pada umumnya ORC untuk sistem sederhananya memiliki empat komponen utama, yaitu pompa, evaporator, turbin dan kondensor. Pompa merupakan salah satu dari komponen penting dari sistem ini, salah satu pompa pada sistem ORC Solar thermal berfungsi untuk mensirkulasikan fluida panas. Fluida panas tersebut berfungsi untuk menguapkan fluida kerja di dalam evaporator (Kreith, 1997). Pada sistem ORC solar thermal, sirkulasi air panas melalui beberapa komponen diantaranya pompa, solar kolektor, evaporator, dan bladder tank serta komponen pendukung, seperti pipa. Untuk peningkatan optimasi pada ORC teradapat 5 poin penting yang perlu diperhatikan yaitu jenis sumber panas yang digunakan, jenis fluida yang bekerja, komponen penyusun ORC, strategi dalam mengatur penggunaan ORC, dan ukuran dan desain dari ORC (Lecompte, et al, 2015)

Dalam pemilihan pompa untuk sirkulasi air panas diperlukan beberapa data yang merupakan input awal sebelum menentukan pilihan dan jenis pompa yang dipergunakan. Data yang diperlukan adalah debit aliran, temperatur, tekanan, densitas, kecepatan aliran fluida di dalam pipa, pressure drop blader tank, pressure drop evaporator dan aliran serta head yang diperlukan untuk mengalirkan zat cair yang akan dipompa (Sularso dan Tahara, 2000).

Penelitian ini berfokus pada pemberian informasi tentang analisis kapasitas dan head loss pompa sirkulasi air panas dan pressure drop yang terjadi pada setiap komponen yang dilalui aliran panas pada sistem ORC Kolektor Surya.Data yang akan digunakan yaitu head loss mayor, minor, evaporator, dan total head loss.

\section{METODE PENELITIAN}

Penelitian ini dilakukan dengan menggunakan metode eksprimen dan simulasi. Adapun alat yang diuji pada penelitian yakni ORC Solar Kolektor. Skema penelitian ORC Solar Kolektor dapat dilihat pada Gambar 1.

Gambar 2 menjelaskan mengenai proses dalam melakukan penelitian ORC ini. Studi pustaka dilakukan untuk mendapatkan sumber referensi terkait ORC dan penggunaan pompa. Selanjutnya, melakukan pengujian pada alat ORC. Data yang didapatkan yaitu tekanan, head loss mayor dan minor.

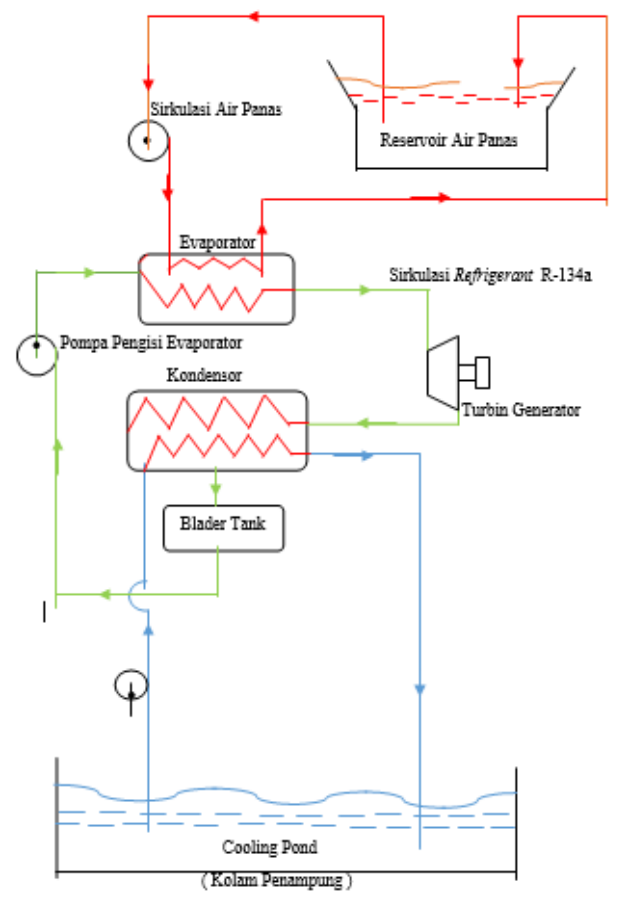

Gambar 1. Skema ORC Solar Kolektor

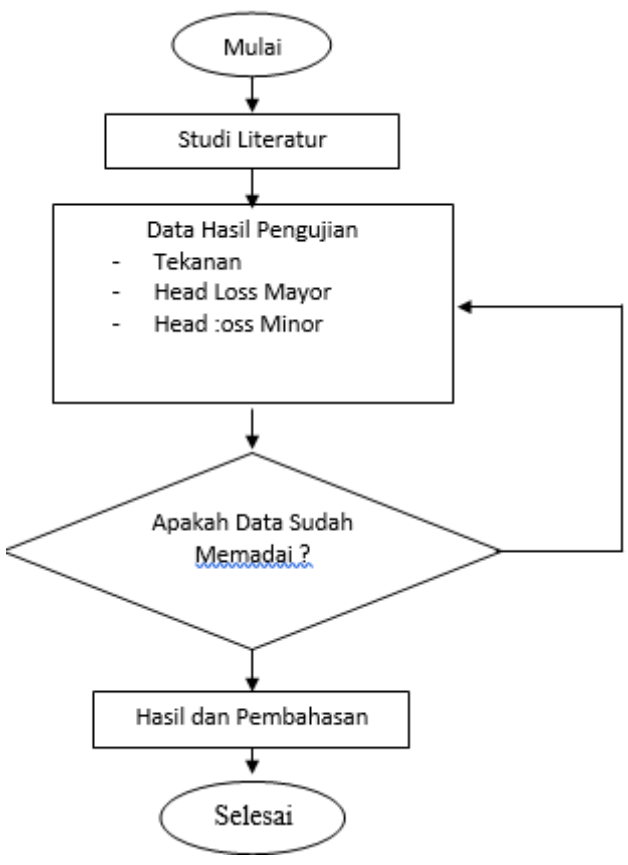

Gambar 2. Diagram alir penelitian 


\section{HASIL DAN PEMBAHASAN}

\subsection{Data hasil pengujian sirkulasi air pada sistem ORC Solar Kolektor}

Dalam melakukan uji eksperimen pompa air pada sistem ORC didapatkan data-data hasil pengujian dapat dilihat pada Gambar 3 dan Tabel 1. Gambar 3 menunjukkan bahwa suhu masuk memiliki nilai yang tinggi dibandingkan dengan suhu keluar dan suhu lingkungan. Kemudian pada Tabel 1 dapat dilihat bahwa nilai tekanan yang dihasilkan relative stabil, hanya pada tekanan di evaporator terdapat kenaikan pada pengambilan data pukul 10 ke pukul 13.

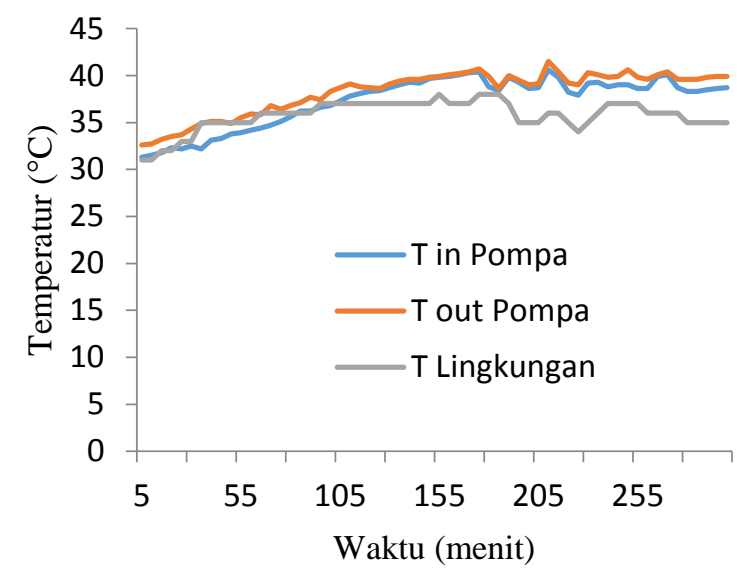

Gambar 3. Grafik hubungan antara temperatur terhadap waktu

Tabel 1. Data hasil pengujian tekanan (P) aliran dengan alat pressure gauge

\begin{tabular}{|c|c|c|c|}
\hline \multirow{3}{*}{$\mathbf{P}$} & \multicolumn{3}{|c|}{ Waktu } \\
\hline & 10.00 & 13.00 & 15.00 \\
\hline & WIB & WIB & WIB \\
\hline $\begin{array}{c}\text { Pout pompa } \\
\text { solar collector }\end{array}$ & 1,93 Bar & 1,93 Bar & 1,93 Bar \\
\hline $\begin{array}{c}\text { Pin pompa } \\
\text { solar collector }\end{array}$ & 0,26 Bar & $0,26 \mathrm{Bar}$ & $0,26 \mathrm{Bar}$ \\
\hline $\begin{array}{l}\text { Pin tabung } \\
\text { Evaporator }\end{array}$ & 0,62 Bar & 0,86 Bar & 0,86 Bar \\
\hline
\end{tabular}

Di bawah ini terdapat grafik nilai tekanan hasil pengukuran pressure gauge.

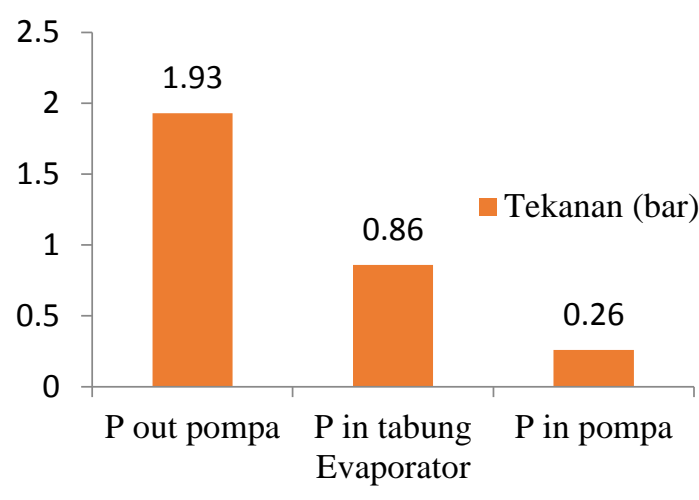

Gambar 4. Hasil pengukuran pressure gauge

Berdasarkan gambar 4, data hasil pengujian tekanan, aliran $P_{\text {out }}=1,93 \mathrm{Bar}=193053 \mathrm{~Pa}$ $P_{\text {in }} 0,26 \mathrm{Bar}=26664 \mathrm{~Pa}$, temperatur air $=37^{\circ} \mathrm{C}$, densitas $(\rho)=993,37 \mathrm{~kg} / \mathrm{m}^{3}$ dan percepatan gravitasi $(\mathrm{g})=9,81 \mathrm{~m} / \mathrm{s}^{2}$, dengan begitu beda tekanan yang terjadi di sepanjang aliran pipa dan komponen ORC dapat dihitung menggunakan rumus (1) dan menghasilkan tekanan pipa delta $\mathrm{P}$ sebesar $17 \mathrm{~m}$.

$\Delta P=\frac{P_{\text {out }}-P_{\text {in }}}{\rho . g}$

$=\frac{193053-26664}{993,37 \times 9,81}=\frac{166389}{9744}=17 \mathrm{~m}$

\subsection{Hasil simulasi pressure drop evaporator}

Gambar 5 menunjukkan hasil simulasi CFD evaporator. Kecepatan inlet memiliki nilai maksimum (berwarna merah) sebesar 29,54 $\mathrm{mm} / \mathrm{s}$. Tekanan inlet berwarna merah yang berarti sebesar 1,27 Pa. Outletnya memiliki warna biru yang berarti memiliki kecepatan minimum dan tekanan yang sangat rendah.

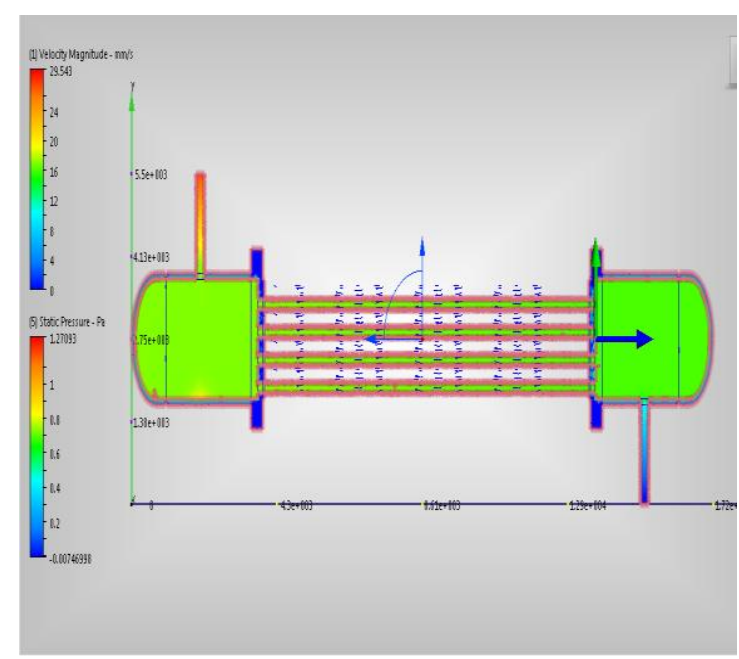

Gambar 5. Hasil simulasi CFD evaporator 


\subsection{Data hasil simulasi evaporator}

Data hasil simulasi evaporator diperlihatkan pada Tabel 2.

Tabel 2. Hasil simulasi evaporator

\begin{tabular}{lc}
\hline $\begin{array}{l}\text { Turbulent } \\
\text { incompressibe } \\
\text { Turbulent Model }\end{array}$ & On \\
$\begin{array}{l}\text { Intelligent Wall } \\
\text { Formulation }\end{array}$ & Standard K-Epsilon \\
Mass Flow In & Off \\
Volume Flow in & $869.023 \mathrm{~g} / \mathrm{s}$ \\
Inlet Bulk & $875.000 \mathrm{~mm}^{3} / \mathrm{s}$ \\
$\begin{array}{l}\text { Pressure } \\
\text { Outlet Bulk }\end{array}$ & $0.72 \mathrm{~Pa}$ \\
$\begin{array}{l}\text { Pressure } \\
\text { Mass Flow Out }\end{array}$ & $0.52 \mathrm{~Pa}$ \\
Volume Flow Out & $-872.975 \mathrm{~g} / \mathrm{s}$ \\
\hline
\end{tabular}

Dilihat dari hasil simulasi $\mathrm{P}_{1}=0,72 \mathrm{~Pa}$ dan $\mathrm{P}_{2}=0,52 \mathrm{~Pa}$. Perhitungan head losses dapat dihitung dengan menggunakan rumus dari penurunan rumus Bernoulli.

$\frac{\Delta P}{\rho g}=\frac{P_{1-} P_{2}}{\rho g}=\frac{0.72-0,52}{933,37 \times 9,81}=2,1 \times 10^{-5} \mathrm{~m}$

\subsection{Perhitungan head}

Hubungan antara faktor gesekan ( $f$ ), bilangan Reynolds (Re) dihitung untuk aliran turbulen,laminar dan transisi, data hasil pengukuran fisik alat uji dan pengujian yang telah dilakukan digunakan untuk menghitung nilai faktor gesekan, $f$ pada aliran turbulen dan laminar, adapun data yang digunakan sebagai parameter perhitungan adalah sebagai berikut:

Parameter yang diperoleh dari pengujian adalah:

1. Temperatur fluida, $(t)=37^{\circ} \mathrm{C}$

2. Density, $(\rho)=993.37 \mathrm{~kg} / \mathrm{m}^{3}$

3. Viscosity, $(\mu)=6,91 \times 10^{-4}$ Pas

4. Debit, $(\mathrm{Q})=0,875 \mathrm{~kg} / \mathrm{s}=0,000875$ $\mathrm{m}^{3} / \mathrm{s}$

5. Percepatan grafitasi, $(g)=9,81 \mathrm{~m} / \mathrm{s}^{2}$

6. Berat jenis fluida, $(\gamma)=9735 \mathrm{~N} / \mathrm{m}^{3}=$ $992,7 \mathrm{kgf} / \mathrm{m}^{2}$

7. Pressure drop out pompa solar kolektor $(\mathrm{P})=28 \mathrm{Bar}$

8. Pressure drop in pompa solar kolektor $(\mathrm{P})=0,26 \mathrm{Bar}$
9. Pressure drop in evaporator, $(P)=0,86$ Bar

10. Rugi-rugi tekanan dalam pipa evaporator $(\mathrm{h})=0,338 \mathrm{Kpa}=0,0347 \mathrm{~m}$

\subsection{Perhitungan major head loss}

Perhitungan major head loss sebagai berikut:

$H_{L_{\text {major }}}=H_{L_{\text {major }} 1}+H_{L_{\text {major }} 2}+H_{L_{\text {major }} 3}+$

$H_{L_{\text {major }}}$

$H_{\text {major }}=0,144573+0,001291+$

$0,047903+2.9=3,093767 \mathrm{~m}$

Jadi besarnya major head loss pada pipa keseluruhan sebesar 3,093767 m.

\subsection{Perhitungan Minor Head Loss}

Berikut perhitungan minor head loss yang terjadi pada pipa sebagai berikut:

$$
\begin{gathered}
H_{L_{\text {minor }}}=H_{L_{\text {minor }} 1}+H_{L_{\text {minor }}}+H_{L_{\text {minor }} 3}+ \\
H_{L_{\text {minor }}}+H_{L_{\text {minor }}}+H_{L_{\text {minor }}}+H_{L_{\text {minor }}}+ \\
H_{L_{\text {minor }}}+H_{L_{\text {minor }} 9}+H_{L_{\text {minor }} 10}+H_{L_{\text {minor }} 11} \\
H_{L_{\text {minor }}}=0,123224+0,18234+0,8 \\
+0,004058+1,1+0,00258 \\
+0,038+0,01+0,008 \\
+0,025+0,468863 \\
=2,762065 \mathrm{~m}
\end{gathered}
$$

\subsection{Perhitungan Total Head Losses}

Total head losses yang terjadi pada pipa keseluruhan dapat dihitung sebagai berikut:

$H_{L}=H_{L \text { major }}+H_{L \text { minor }}+H_{\text {Levaporator }}$ $H_{L}=3,093767+2,762065+0,000021=$ $5,855853 \mathrm{~m}$

Total head loss yang terjadi pada sistem sirkulasi air panas.

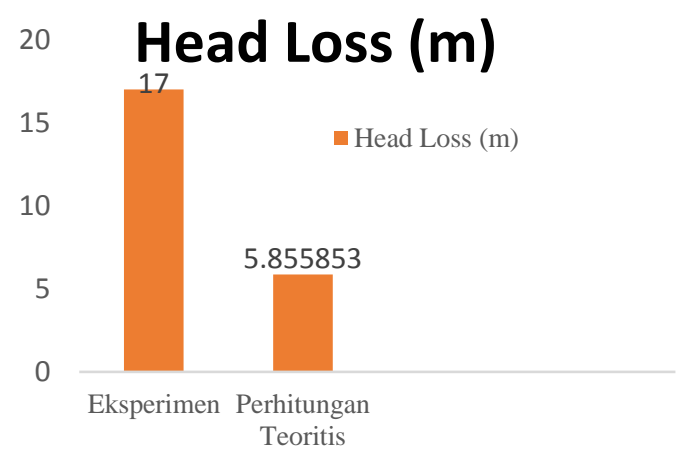

Gambar 6. Grafik total head losses 
Berdasarkan hasil penelitian yang sudah dilakukan oleh Rizal (2014) dan dilihat dari hasil perhitungan head loss yang telah dilakukan menunjukan bahwa pressure drop yang terjadi pada suatu system instalasi pemipaan dilatarbelakangi oleh banyaknya pengunaan komponen pipa, panjang pipa dan jenis pipa yang digunakan.

Pada Gambar 6 menunjukkan hasil eksperimen dan hasil perhitungan teoritis terlihat perbedaan dengan selisih sebesar $11,144147 \mathrm{~m}$, head loss hasil eksperimen lebih besar daripada head loss hasil perhitungan teoritis. Setelah dianalisa hal ini disebabkan oleh beberapa hal diantaranya:

1. Sambungan pipa, pada sistem perpipaan sepanjang aliran sirkulasi air panas banyak menggunakan sambungan las.

2. Kekasaran ekivalen pada material pipa berdasarkan sumber tabel standar kekasaran pipa material kontruksi umum, kekasaran ekivalen pipa yang dihitung kemungkinan berbeda atau tidak akurat karena tidak dihitung menggunakan alat ukur surface raughness tester.

3. Jenis material dan diameter pipa yang beragam, sehingga tekanan air yang terjadi pada saat sirkulasi berubah-ubah sehingga memungkinkan terjadinya head loss.

\section{KESIMPULAN DAN SARAN}

Berdasarkan hasil pengujian tekanan pada sistem sirkulasi air panas dalam sistem ORC Solar Kolektor dapat diperoleh kesimpulan sebagai bahwa terjadi head loss di sepanjang aliran sirkulasi air panas, diantaranya yakni head loss mayor sebesar 3,093767 m, head loss minor sebesar 2,762065 m, dan head loss pada evaporator sebesar $0,000021 \mathrm{~m}$.

Head loss yang terjadi pada sistem sirkulasi air panas dipengaruhi oleh banyaknya jumlah sambungan las dan belokkan pada pipa, serta kekasaran ekivalen pada material pipa, dengan total head loss sebesar 5,855853 m.

Penggunaan pipa sirip longitudinal pada sistem perpipaan sirkulasi air panas tidak bekerja secara optimal, karena head loss yang terjadi pada pengujiaan ini lebih besar dari pada head loss perhitungan teoritis yakni $17 \mathrm{~m}$ berbanding 5,855853 m, terdapat selisih yang cukup besar yakni sebesar $11,144147 \mathrm{~m}$.
Penelitian lanjutan terkait ORC Solar Kolektor ini bisa berfokus pada pemilihan jenis pipa yang digunakan pada sistem sirkulasi air panas ini dan penggunaan sambungan las dan belokan pipa yang lebih sedikit supaya dapat menghindari head loss.

\section{REFERENSI}

Kreith, F. (1997). Prinsip-prinsip perpindahan panas (3 ed.). Jakarta: Erlangga.

Ksayer, E. B. L. (2011). Design of an ORC system operating with solar heat and producing sanitary hot water. Energy Procedia, 6, 389-395. doi: https://doi.org/10.1016/j.egypro.2011.05 .045

Lecompte, S., Huisseune, H., Van Den Broek, M., Vanslambrouck, B., \& De Paepe, M. (2015). Review of organic Rankine cycle (ORC) architectures for waste heat recovery. Renewable and sustainable energy reviews, 47, 448-461.

Rizal, Y. (2014). Analisa pressure drop pada instalasi pipa alat uji rugi-rugi aliran mengunakan CFD Fluent 6.0. Jurnal APTEK, 5(1), 45-56.

Sularso, Tahara, H. (2000). Pompa dan kompresor. Jakarta: Pradnya Paramitha. 